\title{
Epidemiology in Family Medicine
}

\author{
Jose Luis Turabian ${ }^{1,2^{*}}$, Sandra Moreno-Ruiz ${ }^{1,2}$ and Raúl Cucho-Jove ${ }^{1,2}$ \\ ${ }^{1}$ Health Center Santa Maria de Benquerencia, Toledo, Spain \\ ${ }^{2}$ Regional Health Service of Castilla la Mancha (SESCAM) Toledo, Spain
}

*Corresponding author: Jose Luis Turabian, Health Center Santa Maria de Benquerencia, Toledo, Spain, Tel: 34925154508; E-mail: jturabianf@hotmail.com

Received date: October 31, 2016; Accepted date: November 18, 2016; Published date: November 25, 2016

Copyright: ( 2016 Turabian JL, et al. This is an open-access article distributed under the terms of the Creative Commons Attribution License, which permits unrestricted use, distribution, and reproduction in any medium, provided the original author and source are credited.

\begin{abstract}
From a previous publication by the authors about an imported case of Chikungunya (a disease little known in Spain, but with numbers increasing worldwide, and due to the presence of the vector in the Mediterranean area), we show a fable to explain in brief, a deepening on epidemiological implications in family medicine, which is not made in standard textbooks and can be a contribution relevant to the practice of family medicine in their interconnection with epidemiology. The story or metaphor exposed allows induce conceptual categories of how it should look epidemiology, both in infectious diseases and chronic diseases, from family medicine, showing differences, nuances, approaches and practical tools of epidemiological work, which could be applied to any case or patient, and which are different between family medicine and other medical specialties, such as: 1 . the great accessibility of patients to their family doctor, and its role as first contact with the patient ("numerator"); 2.- the continuity of care that allows knowledge of incidence and prevalence rates; 3.- The special method for screening ( "case-finding"); 4.- differences between sensitivity and specificity of diagnostic tests regarding the hospital setting; 5 .- the work with a population as "denominator"; 6.-the conflict between the recommendations of experts in public health and clinical practice with the particular patient (differentiation between frequentist or Bayesian probability); and 7.- the work with small geographic bases.
\end{abstract}

Keywords: Family Practice; Metaphors; Uses of epidemiology; Chikungunya fever

\section{Introduction}

The family physician occupies an important place in the health care of the population, its role as guardian of health, implies a performance aimed primarily at observing and acting on any phenomenon or event that threatens the welfare of the community. The family doctor is the first element or fundamental component of an epidemiological surveillance system, and can be located within the subsystem clinical diagnosis, which is constituted by the network of primary and secondary health care services, outpatient and emergency department.

The person is the center of interest for the family doctor; but the person must be seen "in context". To do this correctly there must be adequate assessment of not only "what health problems there are", but "how many there are and where are" (the incidence and prevalence). The importance of epidemiological research at the family physician level is often forgotten. This epidemiological level today is downplayed or underestimated; however, there have been family physician pioneers who studied the epidemiologic problems of their community with scientific rigor. Some of them have been recognized for their seminal work in the last 125 years [1-5].

Family medicine has important epidemiological connotations, presenting a unique opportunity to study natural history of a disease and to know the rates of diseases in small geographical bases that would facilitate planning and proper use of resources. So, there are specific implications for epidemiology in family medicine which have not been sufficiently systematized conceptually [6].

We have published an imported case of fever due to Chikungunya virus (VCHIK) (Table 1), seen in consultation of family medicine, and in this context from this prior publication [6] of a disease little known in Spain, but with numbers increasing worldwide, and with its vector present in the Mediterranean area, we want to dig a little deeper on the specific implications of epidemiology in family medicine: what are the nuances, approaches, tools and different working practices in epidemiology between family medicine and other medical specialties? $[5,6]$.

Woman 30 years old that says: "I have Dengue or anything similar". She has fever, joint pain and conjunctivitis, having submitted a rash, after returning from Honduras where it is natural, and she is living in Spain for 8 years. In Honduras she lived with a sister and sister in law, in rural area, in a wooden house, for a month, and they had a rash illness with fever and arthralgia. She says "it is Dengue, as there is an outbreak of this disease and knows him well." She says to "know Chagas disease, and she has Dengue". Physical examination: BP: $110 / 80 \mathrm{mmHg}$. Temp: $38.5^{\circ} \mathrm{C}$. There have not lymphadenopathy. Hyperemia bulbar bilateral ophthalmic moderate. Hepatosplenomegaly. Serology was requested against Dengue and Cikungunia, T. cruzi, HIV. It was positive Chikungunia.

Table 1: Clinical observation.

We use, with an educational approach, a short tale or fable to show these characteristics. The fable is an adult education method that can serve to intuitively understand abstract concepts, by linking them to specific situations, and so to facilitate their assimilation. The fable is a brief written narrative that has a didactic purpose; this means that there is a moral or teaching, and it applies to our life. Most of his 
characters are animals that think and speak like they were human beings. In the fable you can distinguish two parts: one is the story itself; and the other the moral.

\section{Discussion}

Family medicine presents a unique opportunity to study the natural history of disease and allows the establishment of patient-physicianfamily-community relationships. Family doctor work includes the natural history of disease and the human life cycle, and so, no one is better able to observe, from family history, the ultimate consequences of any health problem. The simplest and most basic way to achieve effective care is by continuing care. But the family doctor is not an epidemiologist, and we believe that is not equal epidemiology in family medicine vs. other medical specialties. How then differentiate the epidemiology of family medicine specialty? What are the nuances, approaches, tools and different working practices in epidemiology between family medicine and other medical specialties?

According to classical epidemiological triad, epidemiological patterns of infectious diseases depend essentially on factors that influence the likelihood of contact between infectious agent and susceptible person (guest). The external factors act on organisms, and their effect depend of their strength or weakness (Figure 1).

Agent

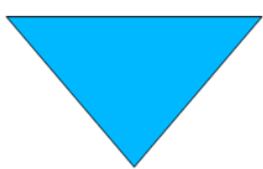

\section{Environment}

Figure 1: "Classic" epidemiological chain.

But this triad has limitations: sometimes the agent or cause is intrinsic to the host or environment. These factors "behind" the chain, behind the agent. The lack of health can be seen as the apex of the pyramid of the health determinants (Figure 2).

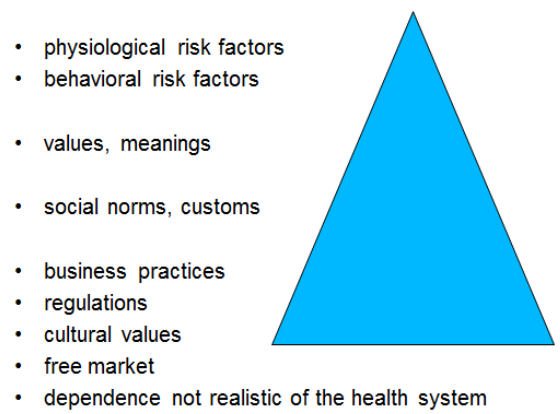

Figure 2: The "lack of health" can be seen, from a wrong view, only as the apex of the pyramid of determinants.

J Gen Pract (Los Angel), an open access journal
The "socioeconomic level" is a health powerful determinant. Wages, education and profession, probably do not directly influence health, but they do it through other variables: tobacco, alcohol consumption, substance abuse, trauma, diet, stress, exposure to infectious or toxic agents, etc. Which tend to be more frequent in socially disadvantaged groups? It can be said, that the social environment is the main determinant of health and disease in any community.

The three key elements of family medicine are the clinical interview, continuity of care and attention to context, and the study of diseases rates are involved in these elements for their calculation and for implementing interventions on the basis of the results. So, in family medicine, we can see a cycle of "individual care - epidemiological or population care" - action and reflection at the level of family medicine consultation", which does not exist in other medical specialties. The key elements of family medicine at the individual level are supporting knowledge of epidemiology at community level, and this knowledge can improve the key tasks of family medicine at individual or patient care level (Figure 3 and Table 2) sets forth the tasks of epidemiological surveillance of the family doctor.

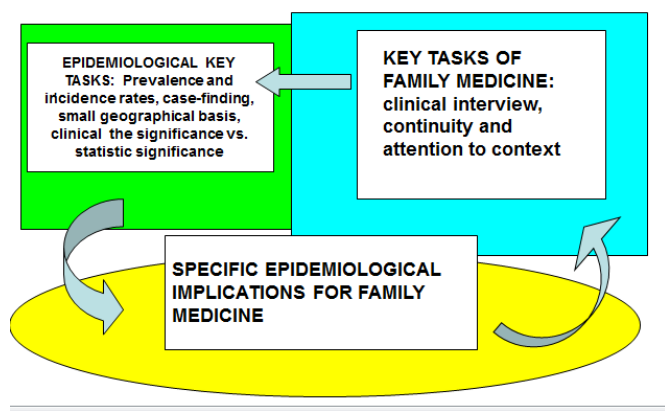

Figure 3: Epidemiology in family medicine.

1. The identification of the population at risk (e.g. immigrants visiting to family and friends for the importation of diseases from their countries of origin).

2 . "Listen to the patient" (eg. in imported diseases, the patient usually it gives clues about their illness, as is familiar with it, because he or she saw other people in your geographical area of origin, which does not the family doctor from another country)

3. The case definition: define the clinical diagnostic criteria from knowledge of the symptoms and signs that appear on the health problem.

4. The detection of the suspected case: is determined by the presence of the characteristics in a high risk group for the disease, and preclinical elements which can be detected by laboratory tests and environmental factors.

5. The application of the epidemiological method for monitoring individual cases: observation of the evolution of infectious or suspected patients and their contacts, looking for those signs and symptoms those patients can ignore, and that are within the case definition.

6. Conducting a true activity of permanent observation in the doctor's office, which should be a quick, safe and systematic source of information reliable data to enable the specialists to perform the analysis, develop hypotheses, draw conclusions and propose and implement actions that every problem requires.

Table 2: Family physician tasks for epidemiological surveillance in infectious diseases.

From the tale presented can be induced conceptual categories that could apply to any case or patient in family medicine: the first thing to do is to known the context, so to can give the right value to the symptoms (the symptoms of VCHIK had been diagnosed as flu if you 
do not put it on its context (trip to Honduras, endemic, etc.), the importance of "listening to the patient" in the interview, the importance of the beliefs that the patient has, the importance of knowing the family context and the "actors" (transmission, involvement of children without immunity, etc.), the importance of knowledge of risk groups, the personal resources for treatment, and the importance of knowing and using community resources.

We can conceptualize and systematize a series of specific epidemiological implications in family medicine:

1. The great accessibility of patients to their family doctor, and its role as first contact with the patient ("numerator").

2. Continuity of care. Family medicine have Important epidemiological connotations, presenting a unique opportunity to study the natural history of a disease and to know the incidence and prevalence rates of diseases in small geographical bases, that would facilitate planning and proper use of resources. Similarly, the natural history of disease is a variable that changes the number of new cases of the disease in the consultation $[7,8]$.

\section{The opportunities for early diagnosis and preventive activities.}

4. The method of identifying pre-symptomatic diseases and screening is done differently: "case-finding" taking advantage of patient visits [9-12].

5. The differences between sensitivity and specificity of diagnostic tests regarding the hospital setting. The negative predictive value (the probability that a certain disease is not the cause of the patient's problem) is more important than the positive predictive value due to the low prevalence of disease vs. the hospital setting $[13,14]$.

6. The working with a population as "denominator". A main element of the family doctor and epidemiologist involves completion of the clinical individual picture (an "iceberg" of total diseases) in family medicine $[15,16]$.

7. The conflict between the recommendations of experts in public health and clinical practice with the particular patient (differentiation between frequentist and Bayesian probability). The frequentist odds are offered by epidemiology, but make individual decisions based on them can be a serious error [17].

8. The work with small geographical bases [18].

9. Treatment of patients with low risk can be a high risk strategy. This means the importance of transforming measures of relative risk in the number of patients who need to be treated to prevent a final event [19].

10. The difference between statistical significance and clinical. Thus the significance (the mathematical probability that the outcome will not occur by chance) is less relevant than the clinical significance: that the results of study could mean if they were applied to a similar population.

11. The assessment of the usefulness of sanitary measures. It is an excellent way to evaluate the process and outcome of health care, simply by comparing the number of cases observed to be expected. Patients in clinical trials are selected to cooperate with the intervention being evaluated. But ordinary patients experience lower rates of success of the intervention that reported in clinical trials.

12. Individual attention and community are not alternatives of care given by family doctor [20].
13. The epidemiological method of family medicine is a bio-psychosocial method [20].

14. The context in family medicine is a non-linear context, without conditions of normality and independence of variables in a complex system [21-23].

\section{Conclusion}

There is an area where merge epidemiology and Family Medicine. Family Medicine presents a unique opportunity to detect new cases of disease, and to study the natural history of it as it contemplates the human life cycle continuously, and no one is better able to observe from family history to the ultimate consequences of any health problem. A good starting point for epidemiological research is the critical analysis of individual patients a man and his little world. For the sensible practice of Family Medicine only the traditional skills of diagnosis and treatment are not enough, but also the application of the understanding of the frequency and distribution of disease in the community and its natural history are necessary. The art of family medicine is to combine the paradigm of personal physician and adviser, with that of epidemiologist with primary care, capable of measuring morbidity, assess needs and priorities for intervention. All this gives rise to specific implications from epidemiology in Family Medicine [24,25].

\section{References}

1. Mackenzie J (2013) A Defence of the Thesis that "The opportunities of the general practitioner are essential for the investigation of disease and the progress of medicine". Int J Epidemiol 41: 1507-1518.

2. Smith BH, Guthrie B, Sullivan FM, Morris AD (2013) Commentary: A thesis that still warrants defense and promotion. Int J Epidemiol 41: 1518-1522.

3. Baker R (2013) Commentary: James Mackenzie 1921, still relevant in 2012. Int J Epidemiol 41: 1523-1525.

4. Hart JT (2013) Commentary: Sir James Mackenzie (1853-1925): An ambiguous pioneer for research in primary care. Int J Epidemiol 41: 1525-1531.

5. Turabian JL, Báez-Montiel B, Gutiérrez-Islas B (2016) Implications of Incidence Rates of Diseases at Local Level in Family Medicine. Scientific Pages of Family Medicine.

6. Turabián JL, Moreno-Ruiz S, Cucho-Jove R (2016) "Doctor, I have Chikungunya". Conceptual systematisation of specific epidemiological implications in family medicine. Semergen 42: 488-491.

7. Fry J (1992) Common Diseases: Their Nature Incidence and Care. (4th edtn), MTP Press Limited, Lancaster, England.

8. Rolland JS (1994) Families, illness, and disability. An integrative treatment model. Basic Books, New York, USA.

9. Hart JT (1970) Semicontinuous screening of a whole community for hypertension. Lancet 2: 223-226.

10. Hart JT (1974) Milroy Lecture: the marriage of primary care and epidemiology: continuous anticipatory care of whole populations in a state medical service. J R Coll Physicians Lond 8: 299-314.

11. Hart JT (1975) Management of high blood pressure in general practice. J R Coll Gen Pract 25: 160-192.

12. Hart JT, Thomas C, Gibbons B, Edwards C, Hart M, et al. (1991) Twenty five years of case finding and audit in a socially deprived community. BMJ 302: 1509 .

13. Morrell D (1988) Epidemiology in General Practice. Oxford: Oxford Medical Publications, England.

14. Leeflang MMG, Rutjes AWS, Reitsma JB, Hooft L, Bossuyt PMM (2013) Variation of a test's sensitivity and specificity with disease prevalence. CMAJ 185: E537-E544. 
Citation: Turabian JL, Moreno-Ruiz S, Cucho-Jove R (2016) Epidemiology in Family Medicine. J Gen Pract (Los Angel) 4: 278. doi: 10.4172/2329-9126.1000278

Page 4 of 4

15. Morris JN (1955) Uses of epidemiology. Br Med J 2: 395-401.

16. Morris JN (2007) Uses of epidemiology. Int J Epidemiol 36: 1165-1172.

17. Frequentistic statistics and inferential statistics. The Bayes Theorem.

18. Ndungu FM, Marsh K, Fegan G, Wambua J, Nyangweso G, et al. (2015) Identifying children with excess malaria episodes after adjusting for variation in exposure: identification from a longitudinal study using statistical count models. BMC Medicine 13: 183.

19. Lewis LS (2015) Combined use of antidepressants and NSAIDs: NNT for intracranial haemorrhage. BMJ 351: h4444.

20. Turabian JL (1995) Family and Community Medicine notebooks. An Introduction to the Principles of Family Medicine. Madrid: Díaz de Santos, Spain.
21. Wilson T, Holt T, Greenhalgh T (2001) Complexity and clinical care. BMJ 323: 685-688.

22. Innes AD, Campion PD, Griffiths FE (2005) Complex consultations and the 'edge of chaos'. Br J Pract 55: 47-52.

23. Martin CM, Sturmberg JP (2005) General practice: chaos, complexity and innovation. Med J Aust 183: 106-109.

24. Watson GI (1982) Epidemiology and research in a general practice. The Royal College of General Practitioners, London, UK.

25. Mc Whinney IR (1989) A textbook of Family Medicine. Oxford University Press, New York, USA. 